\title{
ANÁLISE DE MANIFESTAÇÕES PATOLÓGICAS EM RESIDÊNCIAS UNIFAMILIARES DO BAIRRO SÃO PEDRO - TERESINA PI ${ }^{1}$
}

Marcos Alécio Campos da Silva, Alefen Silva de Sousa, Amanda Fernandes Pereira da Silva, Jassinfla Araújo Silva, João Bráz Araújo Neto, Centro Universitário Santo Agostinho ${ }^{2}$

\section{RESUMO}

Estudos relacionados à Patologia das Construções demonstram um aumento de problemas relacionados às edificações, voltados à habitação popular. Exige-se entender a razão para tais problemas e acompanhar a frequência de ocorrência destes para que, assim, soluções preventivas ou corretivas em projetos, execução e manutenção sejam feitas a fim de evitá-los em outros empreendimentos. Com isso, neste trabalho foi feito uma análise de manifestações patológicas presentes em 3 residências unifamiliares localizadas no Bairro São Pedro, em Teresina. $O$ estudo foi dividido em duas etapas, onde, na primeira, identificou-se através da inspeção visual quais eram as possíveis patologias aparentes em cada uma das residências. Já na segunda etapa, levando em consideração o estado atual em que se encontravam as residências, de forma separada, foi diagnosticado em qual etapa da construção as anomalias podem ter sido causadas, ou se foi na fase de projeto, de execução ou de manutenção. Os problemas avaliados foram basicamente os mesmos entre as unidades estudadas alcançando um resultado de $50 \%$ de manifestações patológicas possivelmente geradas na etapa de execução. De modo geral, a anomalia mais incidente foi relacionada à parte de revestimentos atingindo cerca de $56 \%$. Chegou-se ao entendimento que a quantidade de ocorrências na etapa de execução foi um indício que ainda há muito o que se fazer com relação às medidas que devem ser impostas levando em conta a qualidade e durabilidade aliados à economia em residências unifamiliares.

Palavras-Chave: Patologia. Projeto. Execução. Manutenção.

\section{INTRODUÇÃO}

O crescimento acelerado da construção civil, buscando sempre novas técnicas e materiais de construção, com o objetivo de aumentar a produtividade dentro do canteiro de obras, trouxeram também maiores riscos. Contudo, o conhecimento das consequências da inadequação dessas novas técnicas e materiais nas etapas de uma obra, é indispensável a todos os profissionais da construção civil (ARAÚJO, 2017).

\footnotetext{
${ }^{1}$ Trabalho apresentado no Congresso Brasileiro Ciência e Sociedade (CBCS 2019), promovido pelo Centro Universitário Santo Agostinho, de 03 a 05 de outubro de 2019, em Teresina-PI.

${ }^{2}$ Graduando em Bacharelado em Engenharia Civil, Centro Universitário Santo Agostinho, alecio_campos@hotmail.com; Graduando em Bacharelado em Engenharia Civil, Centro Universitário Santo Agostinho, deyves.95@hotmail.com; Graduanda em Bacharelado em Engenharia Civil, Centro Universitário Santo Agostinho, amandafeernandes09@gmail.com; Graduanda em Bacharelado em Engenharia Civil, Centro Universitário Santo Agostinho,jassinfla@gmail.com;Graduando em Bacharelado em Engenharia Civil, Centro Universitário Santo
} Agostinho, eng.joaobraz@gmail.com. 


\section{CONQGEESOOCIENCIAESOCIEDADE

ANAIS CBCS 2019 | 3 a 5 de outubro de 2019 | Centro Universitário Santo Agostinho - Teresina - PI

As manifestações patológicas têm origem motivada devido às falhas que ocorrem durante a realização de atividades inerentes ao processo de construção civil. Este processo pode ser dividido em três etapas: Projeto, Execução e Manutenção. O diagnóstico adequado deve indicar em qual etapa desse processo teve origem os sintomas, além de ser uma informação importante para a definição de uma solução mais adequada, também tem uma contribuição para a resolução de conflitos judiciais (CARRARO, 2010).

A dificuldade de solução e o custo são diretamente proporcionais à idade da falha, ou seja, um problema na etapa de projeto gera uma solução mais complexa e onerosa do que na etapa de execução. Por isso, um sistema de controle dessas etapas é importante para evitar possíveis manifestações patológicas durante a vida útil do empreendimento (SOUZA; RIPPER, 1998).

Desta forma, o presente trabalho tem como intuito identificar as etapas do processo de construção civil, que mais ocorrem erros, com auxílio de laudos de vistoria, em três residências no bairro São Pedro, localizado em Teresina-PI.

\section{METODOLOGIA}

Esta pesquisa possui caráter quantitativo, a metodologia utilizada foram os estudos de casos de três residências, localizadas no bairro São Pedro, Teresina-PI. Para alcançar o objetivo nesta pesquisa dividiu-se ela em duas etapas:

Etapa I: Consiste em analisar separadamente cada uma das residências, identificando as manifestações patológicas que ocorrem em cada uma das etapas da construção.

Etapa II: Identificar em cada uma das residências as causas de manifestações patológicas geradas na etapa de projeto, execução e manutenção.

\section{RESULTADOS E DISCUSSÃO}

Foram escolhidas como base três residências, todas de caráter unifamiliar, com características semelhantes de localização e padrão econômico, de classe média, com no máximo dois pavimentos. As casas foram escolhidas nas proximidades do Centro universitário Santo 
ANAIS CBCS 2019 | 3 a 5 de outubro de 2019 | Centro Universitário Santo Agostinho - Teresina - PI

Agostinho, com o intuito de beneficiar os moradores da localidade com o fornecimento de laudos de problemas que podem oferecer risco a integridade física do proprietário oferecendo possíveis soluções aos mesmos. As residências foram nomeadas pelas letras " $A$ ", " $B$ " $e$ " $C$ ".

A residência de caráter unifamiliar " $A$ " apresenta um pavimento com um banheiro e quatro dormitórios, possui 290, $17 \mathrm{~m}^{2}$ de área construída, estrutura em alvenaria, forro em PVC e cobertura de madeira. Na parte interna da casa as instalações são aparentes e embutidas e o piso externo com parte de areia natural e outra cimentado. A idade do imóvel compreende cerca de 34 anos.

A residência de caráter unifamiliar " $B$ " apresenta um pavimento com quatro banheiros $\mathrm{e}$ quatro dormitórios, possui 309, $34 \mathrm{~m}^{2}$ de área construída com $560 \mathrm{~m}^{2}$ de área a ser regularizada. A estrutura feita nessa casa é de concreto armado com forro de gesso. A cobertura é de madeira/telha cerâmica e o piso externo de concreto com todas as instalações embutidas.

Já a residência " $C$ " apresenta dois pavimentos com dois banheiros, seis quartos, possui um terreno de $360,00 \mathrm{~m}^{2}$. a estrutura é de concreto armado, com cobertura de telha cerâmica tipo colonial, forro de PVC e com o piso ao longo de todo terreno, exceto na área interna da casa, revestido de concreto. 0 imóvel tem cerca de 30 anos que foi construído.

As ocorrências de manifestações patológicas podem ter vários motivos e causas relacionadas as mesmas, desde fatores internos, como erros de concepção e análise incorreta da modelagem do projeto ou falta de técnicas adequadas na execução ocasionando erros que terão consequências futuras prejudicando a vida útil de estrutura; ou podem ser causados por fatores externos, que são os casos de recalques diferenciados, falta de adequação da estrutura ao ambiente, bem como acidentes e ações imprevisíveis.

Foi utilizado uma planilha de preenchimento simples, com as manifestações patológicas divididas em 7 etapas que decorrem durante o processo de construção e outra tabela que infere a divisão em três partes do processo de vida da estrutura, seja ela na etapa de projeto, construção ou manutenção. Foi marcado com um " $x$ " (observar a Figura 1 e 2) a casa que teve determinada manifestação patológica de acordo com a etapa proposta, onde posteriormente formou-se um gráfico com os índices e indicadores do percentual de frequência da manifestação de cada anomalia. 


\section{cONGQESSO CIENCIASSOCIEDADE \\ Inovação, Diversidadie e Sustentahilitidade}

ANAIS CBCS 2019 | 3 a 5 de outubro de 2019 | Centro Universitário Santo Agostinho - Teresina - PI

FIGURA 1. Tabela com as manifestações patológicas de acordo com as etapas construtivas

\begin{tabular}{|c|c|c|c|}
\hline \multirow{2}{*}{ Manifestações patológicas nas etapas construtivas } & \multicolumn{3}{|c|}{ Residências } \\
\hline & A & B & C \\
\hline 1. Estrutura & \multicolumn{3}{|c|}{ Ocorrências $=3$} \\
\hline Fissuras & $\mathrm{x}$ & & $\mathrm{x}$ \\
\hline Irregularidade geométrica & & $x$ & \\
\hline 2. Revestimento & \multicolumn{3}{|c|}{ Ocorrências = 18} \\
\hline 2.1 Forro & \multicolumn{3}{|c|}{ Ocorrências = 6} \\
\hline Fissuras & $\mathrm{x}$ & & $x$ \\
\hline Manchas & $\mathrm{x}$ & & $x$ \\
\hline Bolhas & & $x$ & \\
\hline Descascamento & & $x$ & \\
\hline 2.2 Paredes de vedação & \multicolumn{3}{|c|}{ Ocorrências = 12} \\
\hline Fissuras & $\mathrm{x}$ & & $x$ \\
\hline Manchas & $x$ & & $x$ \\
\hline Descascamento & $x$ & $x$ & $x$ \\
\hline Bolhas & & $x$ & $x$ \\
\hline Eflorescências & & $\mathrm{x}$ & \\
\hline Mofo & & $\mathrm{x}$ & \\
\hline Descolamento do rodapé & & $x$ & \\
\hline 3. Piso & \multicolumn{3}{|c|}{ Ocorrências = 2} \\
\hline Descolamento Cerâmico & $\mathrm{x}$ & $\mathrm{x}$ & \\
\hline 4. Esquadria & \multicolumn{3}{|c|}{ Ocorrências = 3} \\
\hline Desenvolvimento de ferrugem & & $x$ & $x$ \\
\hline Perda de mobilidade & & & $x$ \\
\hline 5. Instalações Elétricas & \multicolumn{3}{|c|}{ Ocorrências $=3$} \\
\hline Falhas na isolação de circuitos & $\mathrm{x}$ & & \\
\hline Localização de ponto de tomada inadequado & & $\mathrm{x}$ & \\
\hline Quadro de luz sem identificação dos circuitos & & & $x$ \\
\hline 6. Instalações Hidráulicas & \multicolumn{3}{|c|}{ Ocorrências = 2} \\
\hline Falta de tubulação para águas servidas & $\mathrm{x}$ & & \\
\hline Destinação inadequada da água pluvial & & $x$ & \\
\hline 7. Cobertura & \multicolumn{3}{|c|}{ Ocorrências = 1} \\
\hline Presença de goteiras & $\mathrm{x}$ & & \\
\hline
\end{tabular}

Fonte: Excel. Próprio autor, 2019. 


\section{CONGQEESSOCIENCIAESOCIEDADE \\ Inovação, Diversidadie e Sustentahililitadie}

ANAIS CBCS 2019 | 3 a 5 de outubro de 2019 | Centro Universitário Santo Agostinho - Teresina - PI

FIGURA 2. Tabela das causas das manifestações patológicas

\begin{tabular}{|c|c|c|c|}
\hline \multirow{2}{*}{$\begin{array}{l}\text { Causas de manifestações patológicas em etapas do } \\
\text { processo construtivo }\end{array}$} & \multicolumn{3}{|c|}{ Residências } \\
\hline & A & B & C \\
\hline 1. Etapa de projeto & \multicolumn{3}{|c|}{ Ocorrências $=8$} \\
\hline Erro de dimensionamento & & $\mathrm{x}$ & \\
\hline Erro no modelo estrutural & & & $\mathrm{x}$ \\
\hline Falta de tubulação de esgoto & $\mathrm{x}$ & & \\
\hline Falta de juntas de movimentação & $\mathrm{x}$ & & \\
\hline Falha na destinação de água pluvial & & $x$ & \\
\hline Falta de especificação do projeto de instalações elétricas & & & $x$ \\
\hline Erro na localização de ponto de tomada & & $x$ & \\
\hline falta de sistema de coleta de água pluvial & $\mathrm{x}$ & & $x$ \\
\hline 2. Etapa de execução & \multicolumn{3}{|c|}{ Ocorrências = 12} \\
\hline Falta de impermeabilização & $\mathrm{x}$ & $\mathrm{x}$ & $\mathrm{x}$ \\
\hline Falta de verga e contra-verga & & & $x$ \\
\hline Pintura antes da cura total do reboco & $\mathrm{x}$ & $x$ & \\
\hline Disposição incorreta de blocos de alvenaria & $\mathrm{x}$ & & \\
\hline Falta de aderência da peça cerâmica com a base & $\mathrm{x}$ & $x$ & \\
\hline Falta de aderência por presença de material pulverulento & & $x$ & \\
\hline Parede pintada sobre tintas velha & & $x$ & \\
\hline Falta de rejunte entre peças cerâmica & & $x$ & \\
\hline 3. Etapa de manutenção & \multicolumn{3}{|c|}{ Ocorrências $=8$} \\
\hline Pintura das paredes desgastada & $\mathrm{x}$ & $\mathrm{x}$ & \\
\hline Pintura das esquadrias desgastada & $\mathrm{x}$ & $x$ & \\
\hline Fiação elétrica muito antiga & $\mathrm{x}$ & & \\
\hline Aberturas localizadas na cobertura & $\mathrm{x}$ & & $\mathrm{x}$ \\
\hline Limpeza do revestimento cerâmico & & $x$ & \\
\hline
\end{tabular}

Fonte: Excel. Próprio autor, 2019.

Foram encontrados variados tipos de manifestações patológicas, mas que em todas as casas algumas se sobressaíram devido a repetitividade de ocorrências e percentual elevado. Segundo os estudos e análises as anomalias causadas na parte de revestimento são disparadas os problemas que mais se repetem, em $56 \%$ dos casos há algo relacionado a essa etapa da construção, sendo 


\section{CONGQEESSOCIENCIAESOCIEDADE

ANAIS CBCS 2019 | 3 a 5 de outubro de 2019 | Centro Universitário Santo Agostinho - Teresina - P|

seguido por manifestações patológicas na parte estrutural (10\%) e esquadrias (10\%), logo em seguida instalações elétricas (9\%), instalações hidráulicas e piso (6\%) e por último, cobertura (3\%).

A seguir é apresentado o registro fotográfico das patologias que foi realizado na inspeção das residências.

IMAGEM 3. Exemplo de manifestações patológicas na parte de revestimento
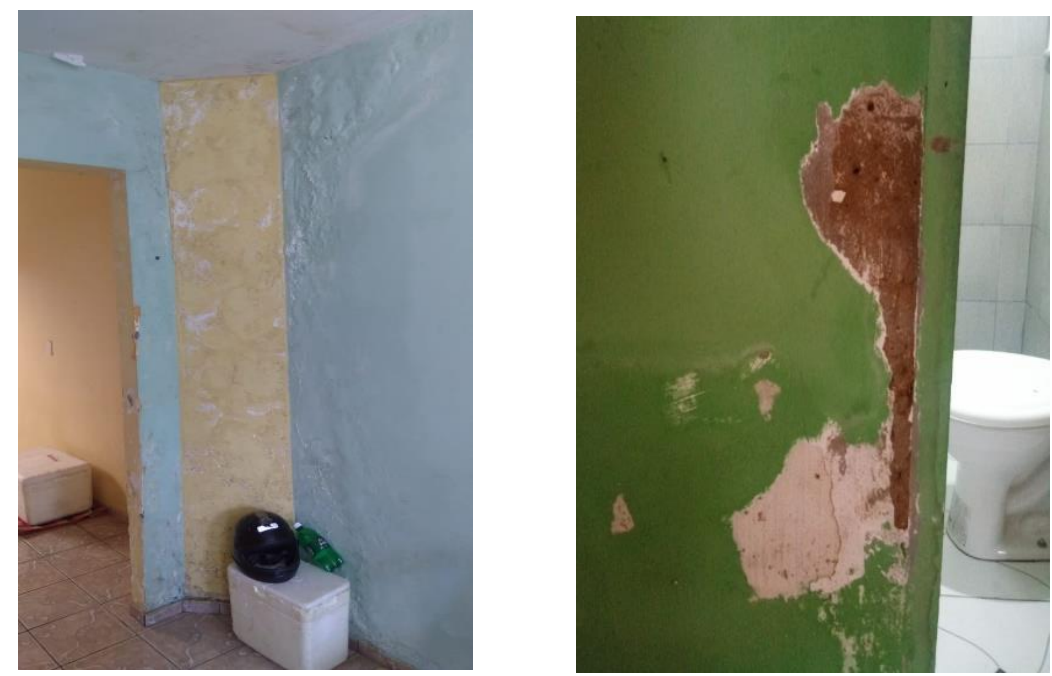

Fonte: Próprio autor, 2019.

IMAGEM 4. Problemas estruturais caracterizados como fissuras e mau dimensionamento de elemento estrutural

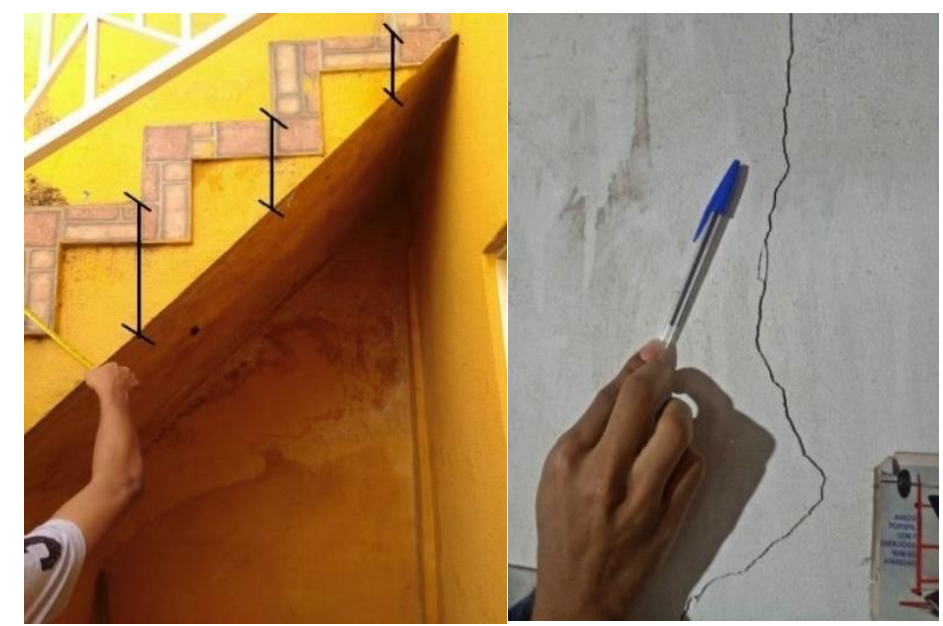

Fonte: Próprio autor, 2019. 


\section{gowerses CIENCIASSOCIEDADE \\ > Inovação, Diversidlatile e Sustentabililitadie}

ANAIS CBCS 2019 | 3 a 5 de outubro de 2019 | Centro Universitário Santo Agostinho - Teresina - PI

IMAGEM 5. Esquadrias com problema de deterioração de ferrugem

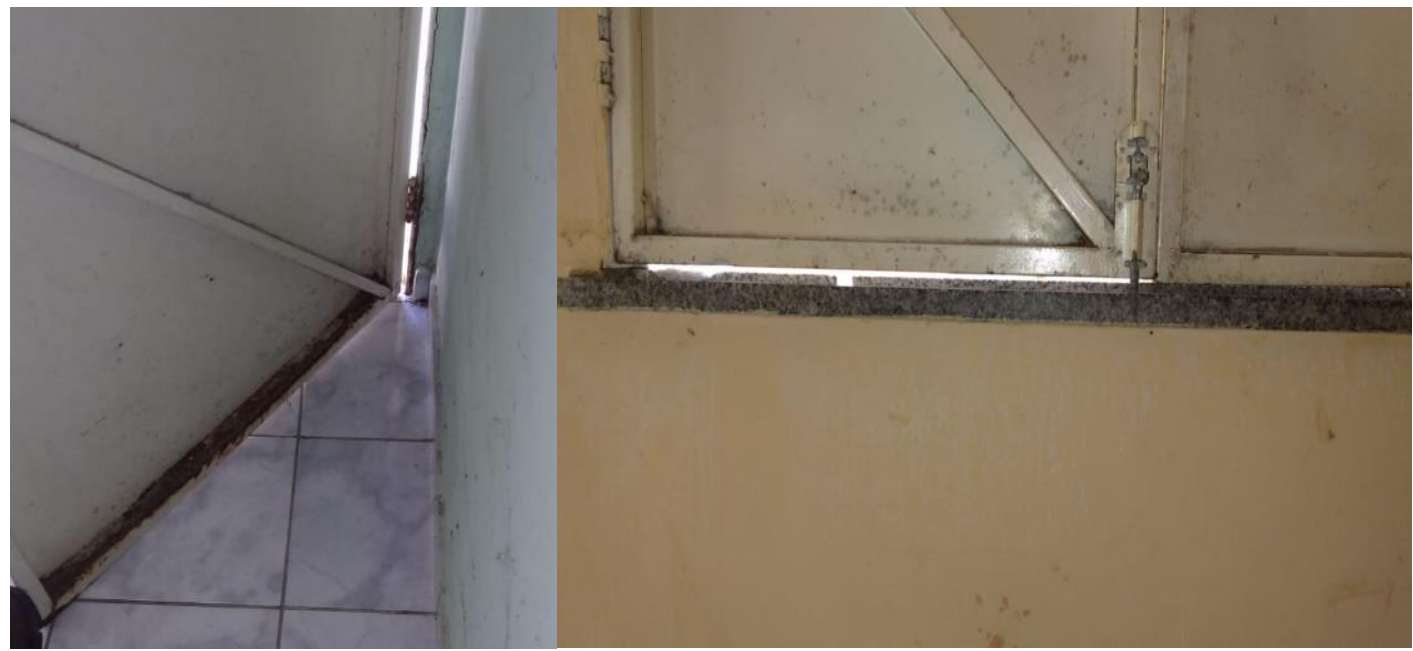

Fonte: Próprio autor, 2019.

IMAGEM 6. Tomada em local inadequado

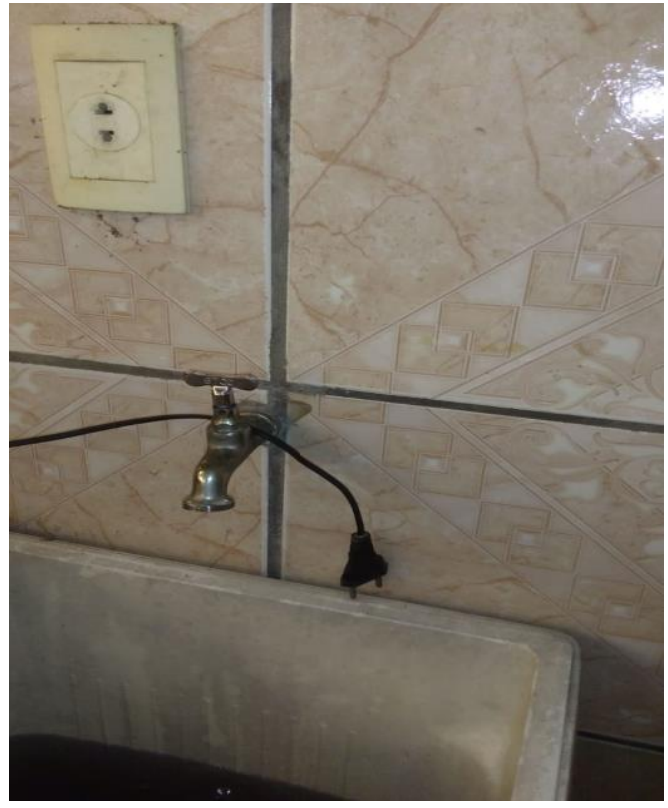

Fonte: Próprio autor, 2019. 


\section{CONQGEESOO CIENCIASSOCIEDADE \\ $\rightarrow$ Inovação, Diversidadle e Sustentahililitadle}

ANAIS CBCS 2019 | 3 a 5 de outubro de 2019 | Centro Universitário Santo Agostinho - Teresina - PI

IMAGEM 7. Tubulação de águas pluviais em local inadequado

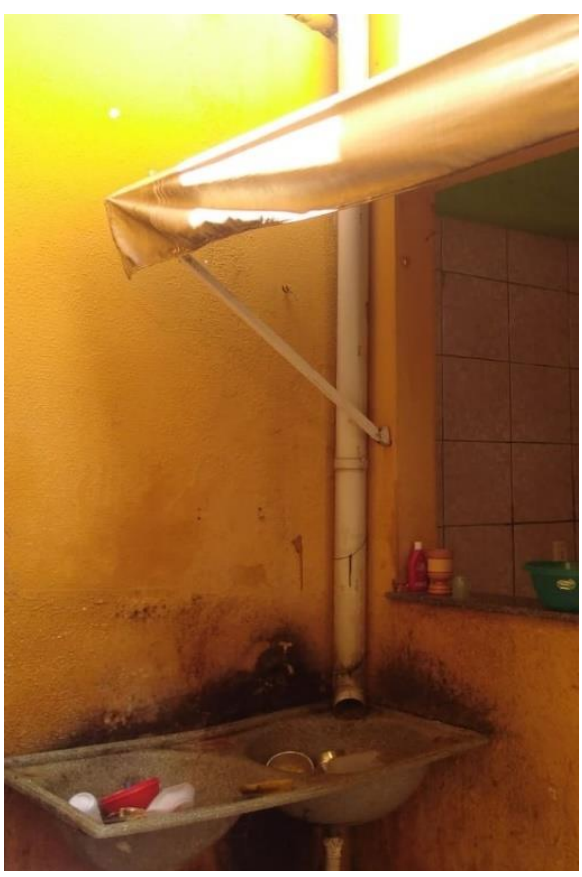

Fonte: Próprio autor, 2019.

IMAGEM 8. Revestimento cerâmico deteriorado

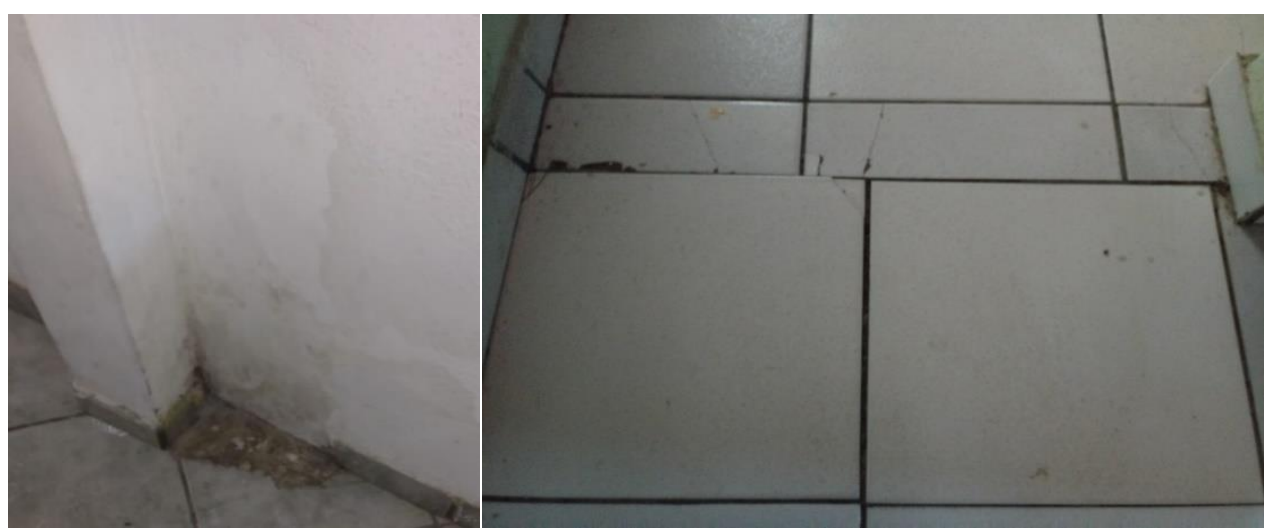

Fonte: Próprio autor, 2019. 


\section{CONGRESSO BRASILERO

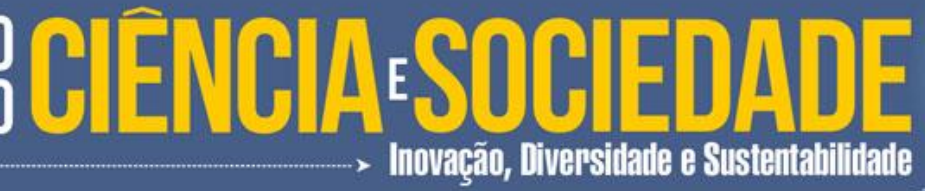

ANAIS CBCS 2019 | 3 a 5 de outubro de 2019 | Centro Universitário Santo Agostinho - Teresina - PI

IMAGEM 9. Telhado com presença de goteiras
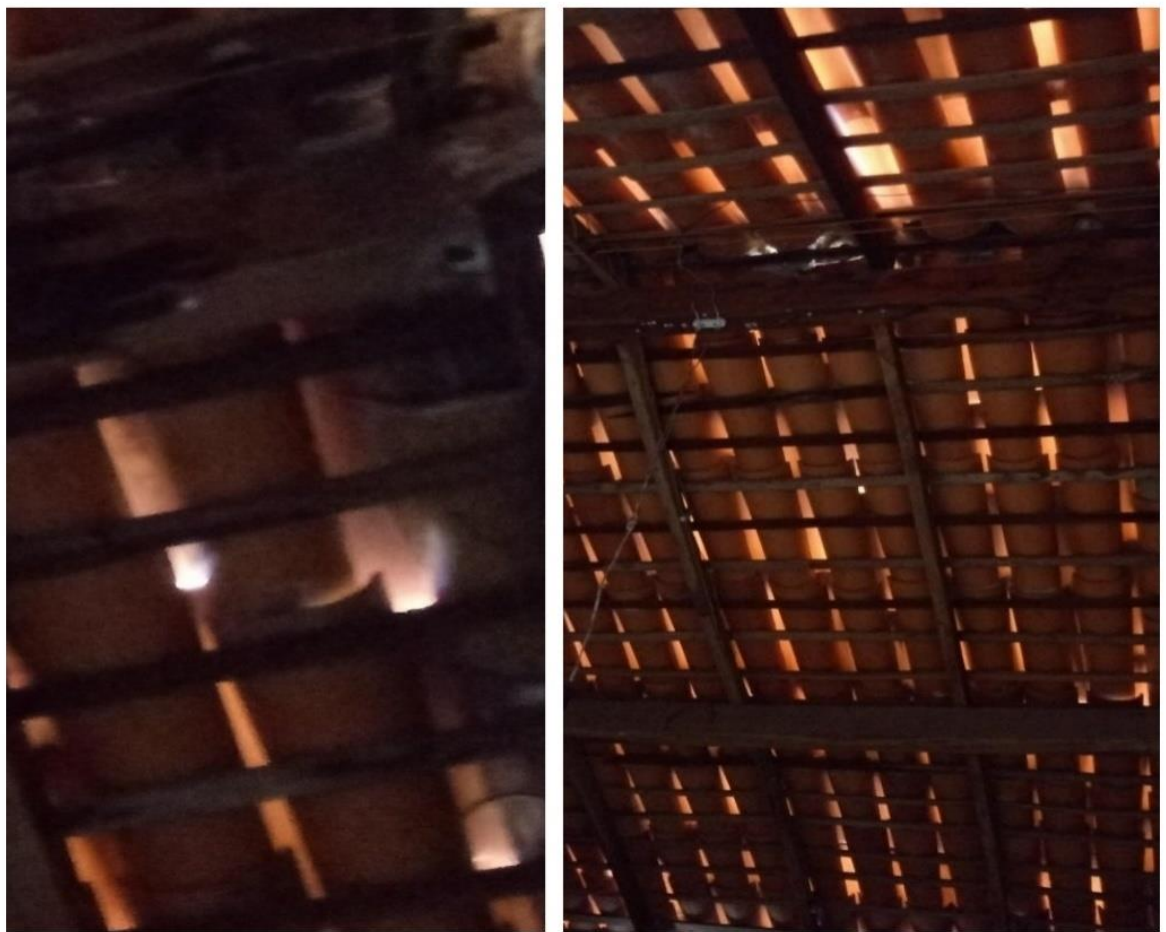

Fonte: Próprio autor, 2019.

De todos os tipos de patologias identificadas foram separadas e classificados como falhas nas etapas do processo de construção, em: etapa de projeto, etapa de execução e etapa de manutenção.

Segundo os fatos analisados a maior responsável por falhas e causas de manifestações patológicas ocorreu durante a etapa de execução da obra (50\%). Seja por falta de entendimento do projeto, material não adequado, mas que na maioria das vezes é pela falta de mão de obra qualificada, ou acompanhamento de profissionais qualificados para a execução de tal atividade. Posterior as patologias causadas na etapa de construção estão as falhas causadas por erro de projeto (25\%) e por falta de manutenção (25\%). Observar as Figuras 10 e 11. 


\section{conweEESSO CIENCIAESOCIEDADE \\ - Inovação, Diversidlatle e Sustentahililitadle}

ANAIS CBCS 2019 | 3 a 5 de outubro de 2019 | Centro Universitário Santo Agostinho - Teresina - PI

FIGURA 10. Grau em porcentagem das manifestações patológicas

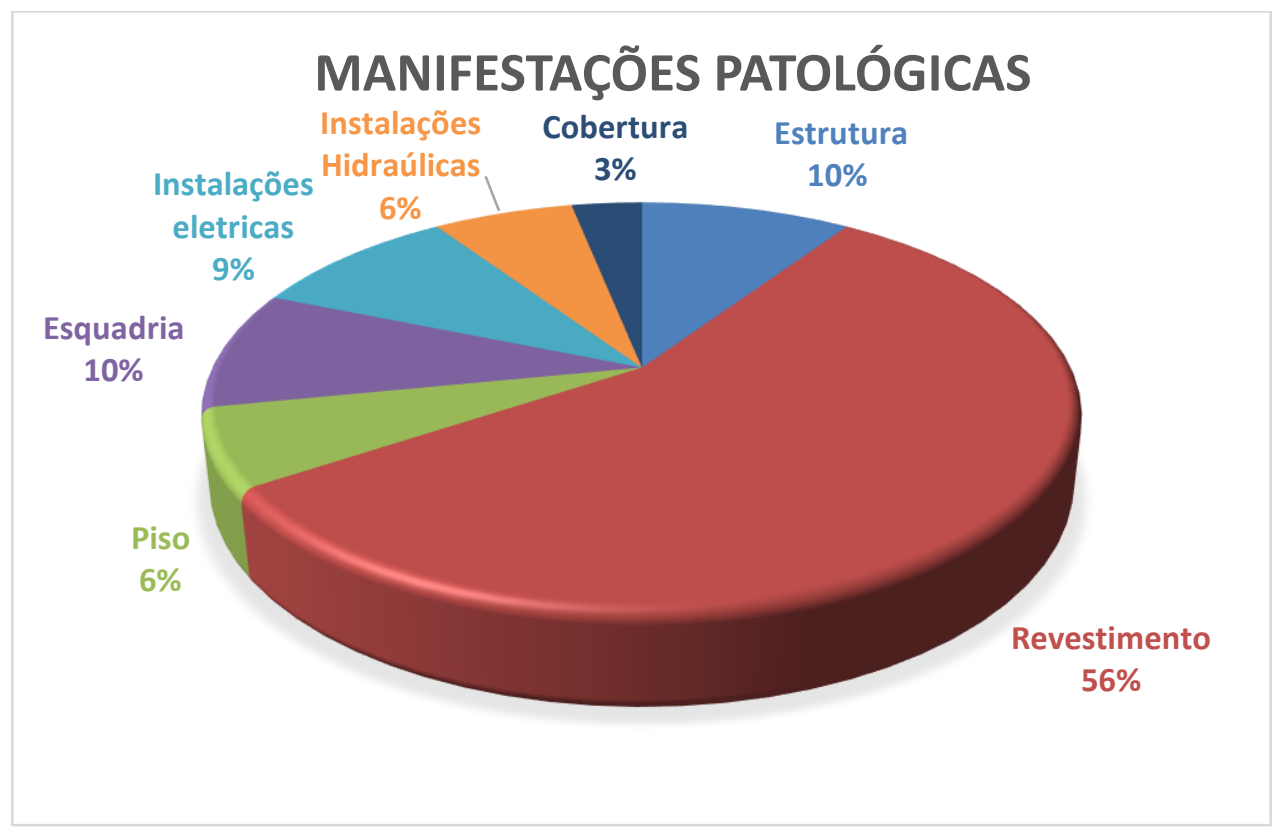

Fonte: Excel. Próprio autor, 2019.

FIGURA 11. Grau em porcentagem das falhas nas etapas do processo construtivo

\section{FALHAS NAS ETAPAS DO PROCESSO CONSTRUTIVO}

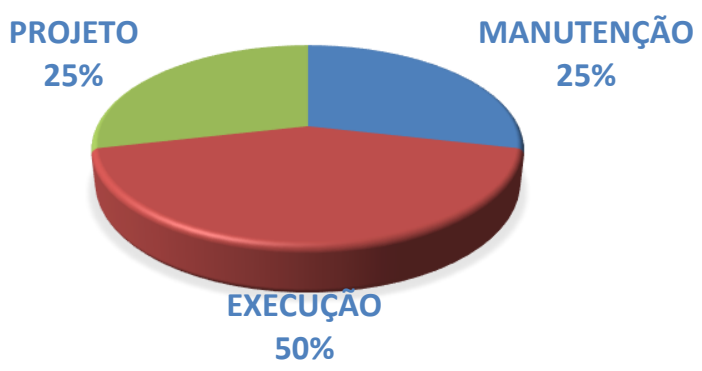

Fonte: Excel. Próprio autor, 2019. 


\section{CONQGEESOOCIENCIAESOCIEDADE

ANAIS CBCS 2019 | 3 a 5 de outubro de 2019 | Centro Universitário Santo Agostinho - Teresina - PI

\section{CONSIDERAÇÕES FINAIS/CONCLUSÕES}

Como a construção civil é suscetível a erros e falhas devido ao trabalho manual, constatouse que a maior parte das manifestações patológicas são originadas, principalmente, pela falta de medidas de execução adequadas. Para que ocorra um tratamento e recuperação dos locais comprometidos com as anomalias, se faz necessário compreender um correto diagnóstico que, se for equivocado, resultará em intervenções inúteis. É importante que a concepção do projeto e o seu planejamento sejam bem elaborados levando em consideração que é preciso, prioritariamente, abranger a técnica da manutenção preventiva para que se tenha uma redução ou até mesmo prevenção de danos graves que comprometam a estrutura em si.

Constatou-se que dentre as 3 residências estudadas, o maior e relevante motivo causador dos problemas presentes foram associados às falhas na execução, com cerca de $50 \%$ comparandose com $25 \%$ em projeto e manutenção. O elemento "Revestimentos" se destacou com a maior frequência de ocorrências com $56 \%$. Há a possibilidade de que as anomalias aparecem mais neste elemento por não ter tido consideração com relação aos tempos de cura das camadas (reboco, emboço e chapisco), ou pela falta de execução de uma das camadas, tinta de má qualidade ou inapropriada para uso externo, entre outros.

Neste cenário, chegou-se à conclusão o quão é preciso melhorar nesse quesito de qualidade associando com a preocupação de que o empreendimento a ser construído seja durável e apresente desempenho satisfatório. Observou-se a precariedade em compreender que as etapas de projeto, execução e manutenção são válidas e precisam ser valorizadas no quesito de como fazer da forma correta baseando-se em critérios de desempenho, durabilidade e vida útil. 


\section{CONQEESSOC CIENCIASSOCIEDADE

ANAIS CBCS 2019 | 3 a 5 de outubro de 2019 | Centro Universitário Santo Agostinho - Teresina - PI

\section{REFERÊNCIAS}

ARAÚJO, M. E. S. O. Análise das manifestações patológicas em edificações escolares pré-fabricadas na cidade de Campinas/SP. Dissertação de mestrado, Universidade Estadual de Campinas, Campinas, 2017.

CARRARO, C. L. Análise pós-obra de habitações de interesse social visando a identificação de manifestações patológicas. Dissertação de mestrado, Universidade Federal de Uberlândia, Uberlândia, 2010.

SOUZA, V. C. M. RIPPER, T. Patologia, recuperação e reforço de estruturas de concreto. São Paulo, 1998. 